\title{
Papers
}

\section{Rapid tranquillisation for agitated patients in emergency psychiatric rooms: a randomised trial of midazolam versus haloperidol plus promethazine}

TREC Collaborative Group

\author{
Abstract \\ Objective To compare two widely used drug \\ treatments for people with aggression or agitation \\ due to mental illness. \\ Design Pragmatic, randomised clinical trial. \\ Setting Three psychiatric emergency rooms in Rio de \\ Janeiro, Brazil. \\ Subjects 301 aggressive or agitated people. \\ Interventions Open treatment with intramuscular \\ midazolam or intramuscular haloperidol plus \\ promethazine.
}

Main outcome measures Patients tranquil or sedated at 20 minutes. Secondary outcomes: patients tranquil or asleep by 40,60, and 120 minutes; restrained or given extra drugs within 2 hours; severe adverse events; another episode of agitation or aggression; needing extra visits from doctor during first 24 hours; overall antipsychotic load in first 24 hours; and not discharged by two weeks.

Results 151 patients were randomised to midazolam, and 150 to haloperidol-promethazine mix. Follow up for the primary outcome was available for 298 (99\%): $134 / 151(89 \%)$ of patients given midazolam were tranquil or asleep after 20 minutes compared with $101 / 150(67 \%)$ of those given haloperidol plus promethazine (relative risk 1.32 (95\% confidence interval 1.16 to 1.49)). By 40 minutes, midazolam still had a statistically and clinically significant $13 \%$ relative advantage (1.13 (1.01 to 1.26)). After 1 hour, about $90 \%$ of both groups were tranquil or asleep. One important adverse event occurred in each group: a patient given midazolam had transient respiratory depression, and one given haloperidol-promethazine had a grande mal seizure.

Conclusions Both treatments were effective. Midazolam was more rapidly sedating than haloperidol-promethazine, reducing the time people are exposed to aggression. Adverse effects and resources to deal with them should be considered in the choice of the treatment.

\section{Introduction}

Health services often manage agitated or violent people, and such behaviour is particularly prevalent in emergency psychiatric services $(10 \%) .{ }^{1}$ Most incidents in psychiatric settings are secondary to severe illnesses such as schizophrenia or substance misuse. ${ }^{2}$ Guidelines recommend that patients should be calmed by use of words and reassurance, a diagnostic history acquired, and physical and laboratory tests completed before drug treatment is started. ${ }^{3}$ However, the acute danger of the situation often makes this impossible, with histories hurried and fragmented, diagnoses speculative, and physical examination impossible. To ensure the safety of everyone involved, rapid tranquillisation of aggressive or violent patients may be unavoidable.

The drugs used in such situations should calm patients safely and swiftly. Guidelines, however, are usually statements of consensus and differ on which drugs to use. ${ }^{3}$ Surveys of clinicians' preferred drug treatments also show variation, ${ }^{56}$ which is confirmed by audit, $^{78}$ although the broad class of older generation antipsychotics and benzodiazepines are often used. ${ }^{19}$ However, given the limited and unconvincing evidence in this subject, variations in guidance and practice are understandable. A trial of zuclopenthixol acetate versus other typical antipsychotics for treating aggressive patients with severe psychiatric illness gave only equivocal results (relative risk of "not tranquil or asleep by 1 hour" of 0.6 (95\% confidence interval 0.3 to 1.3$)$ ). ${ }^{10}$ Similar results were reported for comparisons of benzodiazepines with placebo (relative risk $0.2(0.03 \text { to 1.2) })^{11}$ and of a benzodiazepine-haloperidol mix with haloperidol alone (0.67 (0.3 to 1.4$)){ }^{12}$ There was some suggestion of an effect, however, when haloperidol was compared with placebo $(0.2(0.04 \text { to } 0.9))^{13}$ and benzodiazepines were compared with typical antipsychotics $(0.64$ (0.4 to $0.98)) .^{12}$

The TREC trial (tranquilização rápida-ensaio clínico [rapid tranquillisation-clinical trial]) was a pragmatic randomised trial designed for the psychiatric emergency rooms of Rio de Janeiro. In Rio a relatively low dose mixture of haloperidol, a typical neuroleptic, plus promethazine, an antihistamine with sedative and anticholinergic properties, is used for $80 \%$ of severe psychiatric emergencies, and a benzodiazepine is a second choice, both treatments being given intramuscularly. ${ }^{914}$ Of the two rapidly acting benzodiazepines, midazolam and lorazepam, only midazolam is available in Brazil as lorazepam is unstable at high
Correspondence to: G Huf,

Universidade

Federal do Rio de Janeiro, Núcleo de Estudos de Saúde Coletiva, Av. Brigadeiro

Trompowsky s/n,

Edifício Hospital

Universitário 5

andar, ala sul - Ilha do Fundão, Rio de Janeiro, Brazil, 21941-590, Caixa Postal 68037

gisele@ensp.

fiocruz.br

bmj.com 2003;327:708

Members of the TREC Collaborative Group are listed at the end of the article 
temperatures. Haloperidol, promethazine, and midazolam are on Rio's list of essential drugs, and haloperidol and promethazine are on the World Health Organization's model list of essential drugs. ${ }^{15}$

Most people live in low or middle income countries, and rates of severe mental illness are consistent across the world. ${ }^{16}$ As there is no evidence that psychiatric emergencies are less prevalent anywhere, most episodes of aggression for severely mentally ill people must take place in low or middle income countries. Although new, atypical antipsychotic drugs may become available for use in psychiatric emergencies. These drugs are expensive and are therefore unlikely to affect the care of most people in need of emergency tranquillisation in the near future.

\section{Methods}

TREC was a randomised controlled trial performed in three public psychiatric hospitals in the city of Rio de Janeiro, Brazil. ${ }^{17}$ These hospitals cover about 3.5 million people; half the population of the city. We designed TREC not to interfere with the routine care of people in the participating centres, so eligibility criteria were simple and data collection limited to the minimum.

\section{Selection of patients}

Patients were eligible for trial entry if the treating doctor considered that they needed acute intramuscular sedation because of agitation and dangerous behaviour and if the doctor was uncertain which treatment to use. Patients were ineligible if the clinician believed that one treatment represented an additional risk for the patient.

\section{Intervention and randomisation}

We compared the standard treatment, haloperidol plus promethazine (drawn into the same syringe), with midazolam, both given by intramuscular injection. Doses were at the treating doctors' discretion. We made flumazenil, a benzodiazepine antagonist, available at each centre for use in the event of midazolam toxicity. We supplied the drugs using a local pack system similar to those that had been successful in other large studies in low and middle income countries. ${ }^{18}$

In Britain one collaborator (CEA) used Microsoft Excel to generate even random numbers less than 10 . These block sizes were then applied to a table of random numbers. To help ensure concealment of allocation, CEA produced a table of allocation sequence independent of block size. He sent these tables to a Brazilian colleague independent of the TREC team, who ensured that the correct drug was in the consecutively numbered local pack before it was sealed. These packs were constructed of cardboard, were identical, and were sealed firmly with tape, across which the consecutive number was written. They contained either one ampoule of midazolam $15 \mathrm{mg}$ or two ampoules of haloperidol $5 \mathrm{mg}$ plus one of promethazine $50 \mathrm{mg}$, along with a syringe, needle, swabs, and a follow up form. Verification of order of allocated treatment was monitored throughout the study. ${ }^{17}$ If a patient met the eligibility criteria, the treating clinician took the next consecutive box.

\section{Outcomes}

Part of an earlier survey of psychiatric emergency room practice in Rio was to ask nursing and medical staff for their outcome of primary interest for emergency tranquillisation. ${ }^{9}$ The staff chose "tranquillised or asleep by 20 minutes." Patients were considered tranquillised when they were calm and peaceful-that is, neither agitated nor restless, and not showing threatening verbal behaviour or physical aggression against objects, other people, or themselves.

Secondary outcomes were patients asleep by 20 minutes; tranquil or asleep by 40,60, and 120 minutes; physically restrained or given additional drugs within two hours; severe adverse events; having another episode of agitation or aggression; needing extra visits from the treating doctor during the subsequent 24 hours; overall antipsychotic load in the first 24 hours; and still in hospital after two weeks. As this study was designed not to burden routine practice, we were restricted to the information reliably recorded in medical notes, such as those adverse effects considered dangerous.

\section{Procedures}

Before opening a TREC box, and while still blind to the allocated treatment, a participating doctor completed the form printed on its top. This constituted trial entry. This form recorded the doctor's estimate of the severity and cause of the episode of agitation or aggression. ${ }^{17}$ The box was then opened, the treatment given, and a timer was set to ring every 20 minutes for the first hour. When the timer rang the attending nurse assessed the outcomes. Other data were extracted from the patient's notes.

The accuracy of assessment of primary outcome was checked by other raters, nurses or doctors not involved in the management of the emergency. Blind to the allocated treatment, and unknown to the clinicians looking after the patient, they timed the period between injection and tranquillisation or sleep for $10 \%$ of patients.

\section{Sample size}

In such a stressful situation, even a small advantage for an intervention could represent a worthwhile benefit. Every additional minute of aggression exposes everyone to danger. We aimed to detect difference in the proportion of patients tranquillised by 20 minutes: to detect a difference between groups of at least $20 \%$ at $5 \%$ level of significance ( $\alpha$ error) and $80 \%$ probability $(1-\beta$ error), we needed 300 patients.

\section{Statistical analysis}

We assessed randomisation by comparing (without use of statistical tests) sociodemographic and clinical characteristics between the two treatment groups and calculated relative risks and number needed to treat (with 95\% confidence intervals) for primary and secondary outcomes using intention to treat analysis. We calculated and interpreted confidence intervals for numbers needed to treat according to Altman. ${ }^{19}$ We evaluated statistical significance at the $5 \%$ level for the primary outcome and at $1 \%$ for secondary outcomes. We used $\kappa$ statistics for estimating inter-rater agreement for the primary outcome. We entered data in Epi-Info 6.04 and analysed them with SPSS 9.0. 


\section{Ethical issues}

Most eligible patients are brought to the emergency rooms by the police without relatives and are not able to give consent for participation. Trials without patients' consent are considered justifiable on two conditions: firstly, no other context exists in which to answer the question, and, secondly, all trial patients get clear therapeutic benefit from whichever treatment arm they are allocated to. ${ }^{20-22}$ If relatives were present, they were fully informed and their consent requested. We compared standard care in Rio (haloperidol plus promethazine) with midazolam, a drug used routinely for tranquillisation elsewhere and available to every public hospital in Rio. Our protocol was approved by the Brazilian Council of Ethics in Research, the ethics committees of all the institutions involved, and a local group representing the relatives of mentally ill people.

\section{Results}

Between June and December 2001, 301 patients were randomised to treatment, $95 \%$ between 8 am and midnight, and $16 \%$ at the weekend. The principal investigator $(\mathrm{GH})$ estimated the numbers of eligible people not randomised during that period through observation of 80 aggressive episodes. Two of the 80 people were ineligible, and 20 of the remainder could not be included as no beds were available in participating centres. The rest were randomised. For the primary outcome, data were available for $298(99 \%)$ people (see figure).

Patients in the two treatment groups had similar baseline characteristics and estimated severity of agitation (table 1), suggesting that randomisation was successful. The experienced staff estimated most patients to be markedly disturbed as a result of psychosis (table 1). The patients' demographic and diagnostic characteristics were as expected from the characteristics of the client population who receive emergency psychiatric intervention in the three hospitals in Rio de Janeiro.

The time from injection to tranquillisation or sleep was checked by independent observers for $24(8 \%)$ of the patients. For 22 of these patients there was full agreement. The two discrepancies resulted from an observer's estimate being 10 minutes greater than that of the attending nurse, and from a tranquillised patient being roused to become aggressive again by another patient (estimated overall $\kappa=0.83$ after adjustment for prevalence).

Of the 148 patients given haloperidolpromethazine mix, 77 were given $5 \mathrm{mg}$ of haloperidol and 71 were given $10 \mathrm{mg}$, while 147 were given $50 \mathrm{mg}$ of promethazine and one was given $25 \mathrm{mg}$. Of the 150 patients given midazolam, 124 were given $15 \mathrm{mg}$ and 26 were given $7.5 \mathrm{mg}$.

\section{Outcomes}

Table 2 shows the outcomes for the two treatments. By 20 minutes after injection, $32 \%$ more of the patients given midazolam were tranquil or asleep compared with those given haloperidol-promethazine (number needed to treat for one extra patient to be tranquillised $=5$ (95\% confidence interval 3 to 8$)$ ). By 40 minutes, although most patients were tranquil or asleep, midazolam still had a statistically and clinically

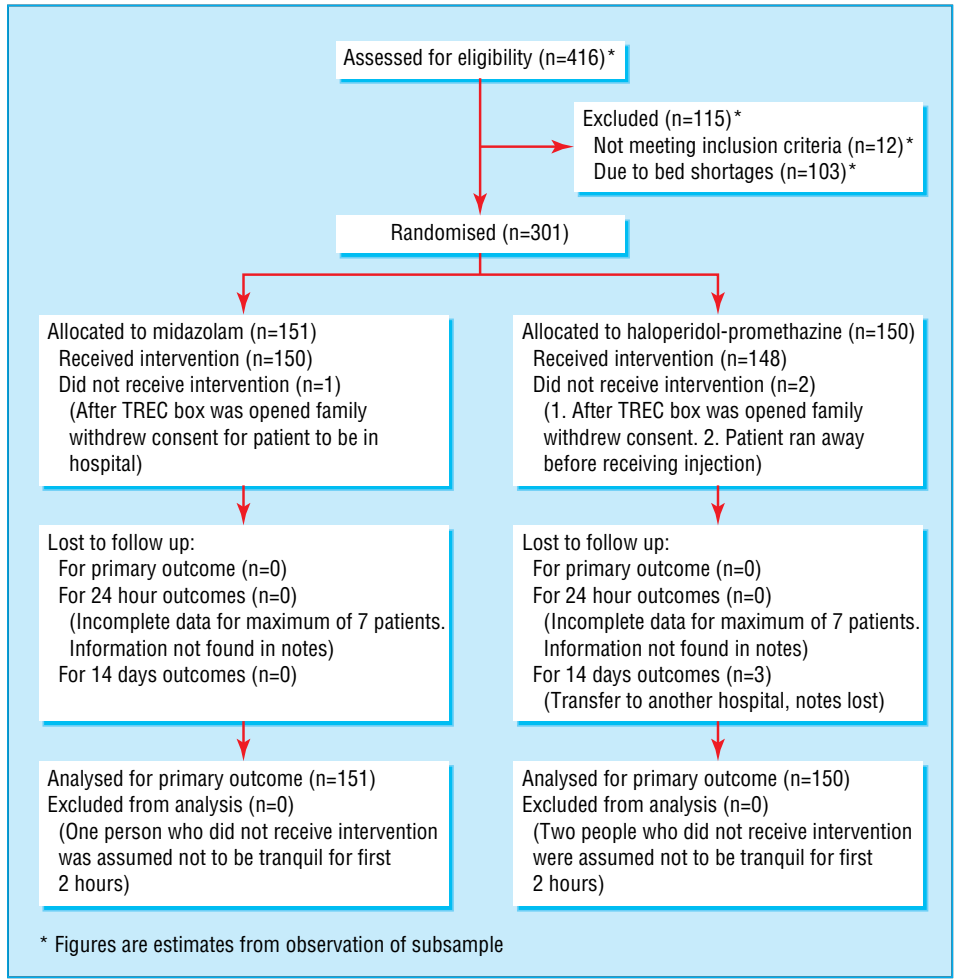

Flow of patients through various stages of TREC study

significant 13\% relative advantage. By an hour, about $90 \%$ of both groups were tranquil or asleep.

Twice as many of the patients given midazolam were asleep by 20 minutes as were those given haloperidol-promethazine. This difference remained statistically and clinically significant up to two hours after injection. Midazolam rapidly sedated patients and kept most sedated for up to two hours. The haloperidol-promethazine mix tranquillised and sedated patients, but with a slower onset of action. A post hoc analysis of response according to diagnosis (psychosis or substance misuse) and severity of disturbance found no differences (data not shown).

Two severe adverse events were reported, one in each group and both within the first 20 minutes after drug administration. One aggressive woman who had epilepsy was given haloperidol $(5 \mathrm{mg}$ ) plus promethazine $(50 \mathrm{mg})$ and had a grande mal seizure 15 minutes after injection. With benzodiazepines, she settled and recovered swiftly. A man with alcohol

Table 1 Baseline demographic and clinical characteristics of 301 patients given midazolam or haloperidol-promethazine mix for emergency intramuscular sedation because of agitation and dangerous behaviour. Values are number (percentage) of patients unless stated otherwise

\begin{tabular}{lcc} 
& Midazolam $(\mathbf{n}=\mathbf{1 5 1 )}$ & $\begin{array}{c}\text { Haloperidol-promethazine } \\
(\mathbf{n}=\mathbf{1 5 0})\end{array}$ \\
\hline Men & $72(48)$ & $74(49)$ \\
\hline First psychiatric attendance & $14(9)$ & $12(8)$ \\
\hline Severity of agitation: & $56(37)$ \\
\hline Moderately & $52(34)$ & $93(62)$ \\
\hline Markedly & $99(66)$ & $112(75)$ \\
\hline Presumed cause: & & $21(14)$ \\
\hline Psychosis & $107(71)$ & $16(11)$ \\
\hline Substance misuse & $30(20)$ & $38(12)$
\end{tabular}


Table 2 Outcomes for 301 patients given emergency intramuscular sedation with midazolam or haloperidol-promethazine mix because of agitation and dangerous behaviour. Values are number (percentage) of patients unless stated otherwise

\begin{tabular}{|c|c|c|c|c|}
\hline Patient outcomes & Midazolam ( $\mathrm{n}=151)$ & $\begin{array}{l}\text { Haloperidol-promethazine } \\
\qquad(\mathrm{n}=150)\end{array}$ & Relative risk (CI)* & Difference in \% risk (Cl)* \\
\hline \multicolumn{5}{|l|}{ By 20 minutes after injection } \\
\hline Tranquil or asleep & $134(89)$ & $101(67)$ & $1.32(1.16$ to 1.49$)$ & 22 (12 to 30$)$ \\
\hline Asleep & $93(62)$ & $43(29)$ & 2.15 (1.48 to 3.11$)$ & 33 (19 to 47$)$ \\
\hline Serious adverse effect & $1(1)$ & $1(1)$ & & \\
\hline Unknown & $1(1)$ & $2(1)$ & & \\
\hline \multicolumn{5}{|l|}{ By $\mathbf{4 0}$ minutes after injection } \\
\hline Tranquil or asleep & $141(93)$ & $124(83)$ & 1.13 (1.01 to 1.26$)$ & $10(1$ to 20$)$ \\
\hline Asleep & $118(78)$ & $69(46)$ & 1.70 (1.32 to 2.19$)$ & 32 (18 to 46$)$ \\
\hline Unknown & $1(1)$ & $2(1)$ & & \\
\hline \multicolumn{5}{|l|}{ By 60 minutes after injection } \\
\hline Tranquil or asleep & $141(93)$ & $131(87)$ & $1.07(0.97$ to 1.18$)$ & $6(-3$ to 15$)$ \\
\hline Asleep & $120(79)$ & $83(55)$ & 1.44 (1.16 to 1.78$)$ & 24 (11 to 38$)$ \\
\hline Unknown & $1(1)$ & $2(1)$ & & \\
\hline \multicolumn{5}{|l|}{ By 120 minutes after injection } \\
\hline Tranquil or asleep & $144(95)$ & $138(92)$ & $1.04(0.96$ to 1.12$)$ & $3(-4$ to 11$)$ \\
\hline Asleep & $125(83)$ & $95(63)$ & 1.31 (1.08 to 1.57$)$ & 20 (7 to 32$)$ \\
\hline No additional tranquillising drugs & 149 (99) & $143(95)$ & 1.04 (0.98 to 1.09$)$ & $4(-2$ to 8$)$ \\
\hline Not needing restraints & $118(78)$ & $110(73)$ & $1.07(0.90$ to 1.26$)$ & $5(-8$ to 18$)$ \\
\hline Unknown & $1(1)$ & $2(1)$ & & \\
\hline \multicolumn{5}{|l|}{ By 24 hours after injection } \\
\hline No other episode of aggression: & $107(71)$ & $111(74)$ & $0.96(0.80$ to 1.15$)$ & $-3(-16$ to 10$)$ \\
\hline Unknown & $2(1)$ & $7(5)$ & & \\
\hline Doctor not called to see patient: & $100(66)$ & $107(71)$ & $0.93(0.76$ to 1.13$)$ & $-5(-19$ to 8$)$ \\
\hline Unknown & $2(1)$ & $4(3)$ & & \\
\hline Accepting oral medication: & $135(89)$ & $139(93)$ & $0.96(0.88$ to 1.06$)$ & $-4(-12$ to 5$)$ \\
\hline Unknown & $7(5)$ & $5(3)$ & & \\
\hline \multicolumn{5}{|l|}{ By 2 weeks after injection } \\
\hline Discharged & $73(48)$ & $69(46)$ & $1.05(0.77$ to 1.44$)$ & $2(-12$ to 17$)$ \\
\hline Unknown & 0 & $3(2)$ & & \\
\hline
\end{tabular}

${ }^{*} 99 \%$ confidence intervals, except for primary outcome (tranquil or asleep by 20 minutes), which is $95 \%$.

induced, and perhaps also cocaine induced, aggression was given midazolam $(15 \mathrm{mg})$. His respiratory rate fell immediately, and he became cyanotic; by 15 minutes his respiratory rate was 32 breaths/minute. He recovered fully after being given flumazenil 0.25 mg intravenously.

Additional tranquillising drugs were rarely needed in the first two hours, and no difference between the groups was apparent. Restraints were used for 73 people, with no statistically significant difference between the groups, though the fact that $5 \%$ fewer people in the midazolam group needed restraints by two hours may be considered clinically significant.

During the first 24 hours, 74 people had another significant episode of aggression. Although there was no statistically significant difference between the two treatments, $6 \%$ more of the patients given midazolam experienced a second episode of aggression.

Most of the patients accepted oral medication, and giving a benzodiazepine did not seem to affect patients' total load of antipsychotic drugs in the first 24 hours. The mean doses in chlorpromazine equivalents during the first 24 hours were $368 \mathrm{mg}$ (SD 283, median 333) for the midazolam group, and $355 \mathrm{mg}$ (SD 267, median 333) for the haloperidol-promethazine group (two sided permutation test $\mathrm{P}=0.67$ ).

After two weeks, 73 (48\%) of the patients who had been given midazolam were discharged, compared with $69(46 \%)$ of those given haloperidolpromethazine (relative risk 1.05 (0.77 to 1.44$)$ ).

\section{Discussion}

This study evaluated the effect of two widely available and inexpensive drug treatments for emergency tranquillisation of aggressive or agitated patients with mental illness. Relatively low doses of both treatments were rapidly effective. However, about a third more people given midazolam were tranquil or asleep by 20 minutes compared with those given haloperidolpromethazine. One in five people remained disturbed for 40-60 minutes longer if given haloperidolpromethazine rather than midazolam. Tranquillisation to sleep was more common with midazolam than with haloperidol-promethazine. Use of the benzodiazepine had no apparent consequences for long term care.

Both drug regimens seemed reasonably safe. A seizure occurred in a person with epilepsy, and respiratory depression occurred in someone whose risk had been increased by substance misuse. Fits and respiratory depression were easily reversed with no repercussions. The results of this study are applicable to general emergency rooms and inpatients in psychiatric and other settings, but the resources available for managing adverse effects should be considered.

Few of the patients required additional drugs in the first two hours after treatment, but a fifth of patients were restrained during this period. In Rio de Janeiro it is more common to put patients who are still not tranquillised in restraints rather than giving them more drugs. ${ }^{9}$ 


\section{What is already known on this topic}

Emergency tranquillisation of violent mentally ill people is sometimes necessary

Guidelines differ on which drugs to use, and the evidence is limited and unconvincing

\section{What this study adds}

This large pragmatic randomised study in Rio de Janeiro compared midazolam with a mixture of haloperidol plus promethazine

By 20 minutes after injection, midazolam tranquillised $89 \%$ of people compared with $67 \%$ tranquillised by haloperidol-promethazine

Serious adverse effects for both treatments were rare, but resources to deal with them should be considered in the choice of the treatment

\section{Strengths and limitations of study}

Trials evaluating the management of aggressive or violent people are rare and usually small. ${ }^{11-14} 2324$ TREC is large in comparison, with a completeness of data collection not seen even in short duration randomised trials for psychoses. This study took place in a middle income country, because of the commitment of clinicians, institutions, ethics committees, and consumer groups to base local practice on good evidence. The pragmatic design, rare in mental health trials, simplified rather than complicated everyday practice. This strategy increased the chance of selecting a sample of patients representative of those who usually attend the emergency rooms. This study provides a reference for those evaluating new drugs for psychiatric emergencies.

This study evaluated the open giving of the two treatments. Blinding of outcome was never envisaged, and the experienced healthcare professionals who participated could accurately tell if and when a person was asleep or tranquil.

\section{Conclusions}

Both treatments worked, but midazolam was clearly more effective than haloperidol-promethazine in terms of rapid sedation. Serious adverse effects for both treatments were rare. Even in the chaos of a busy psychiatric emergency room, these adverse effects should never threaten life. Health professionals might prefer to use midazolam in circumstances where rapid sedation is necessary and after which good observation is possible. Where good observation is impossible, or rapid sedation not paramount, the haloperidolpromethazine mix might be preferred. Consistent clinical practice in Brazil $^{9}$ is now supported with evidence, and other countries that use the haloperidolpromethazine mix (such as India) or midazolam (such as Australia and Thailand) can also be more informed.

The success of this trial is due to the work, skill, and enthusiasm of 37 doctors and 96 nurses and clerks from the psychiatric hospitals of Rio de Janeiro-Instituto Phillipe Pinel, Hospital Municipal Jurandyr Manfredini, and Instituto Municipal de Assistência à Saúde Nise da Silveira. We thank Lelia Duley and Gill Rizzello for help with the final manuscript.

The members of the TREC Collaborative Group are: Gisele Huf (Universidade Federal do Rio de Janeiro, Rio de Janeiro, Brazil);
Evandro S F Coutinho (Fundação Osvaldo Cruz, Rio de Janeiro); Clive E Adams (University of Leeds, Leeds); Raul V S Borges, Marco A V Ferreira, Francisco J F Silva, André J C R Pereira, Francisca M Abreu, Simone M Lugão (Instituto Municipal Philippe Pinel, Rio de Janeiro); Marcelo P C P Santos, Marcio Gewandsznajder, Valéria R P Mercadante (Hospital Municipal Jurandyr Manfredini, Rio de Janeiro); Walmor Lange Jr, Carla L Dias (Instituto Municipal de Assistência à Saúde Nise da Silveira, Rio de Janeiro). The members of the TREC Steering Committee are: Marco Antônio Brasil (chair), Gisele Huf, Evandro S F Coutinho, Clive E Adams, Hugo Marques Fagundes Jr, José Ramón RA Lopez, Maurício Lima, Mário Barreira Campos, Suely Rozenfeld, and Rosaura Maria Braz. The members of the Data Monitoring Committee are: Claudio Jose Struchiner (chair), Luiz B Camacho, Jair de Jesus Mari. Contributors: GH, ESFC, and CEA had the idea for the study and led the development of the protocol, securing of funding, study administration, data analysis, interpretation of results, and writing of the paper. RVSB, MAVF, FJFS, AJCRP, MPCPS, MG, WL, FMA, SML, VRPM, and CLD contributed to collection of data and quality control of data collection. GH, ESFC, CEA are guarantors for the study.

Funding: No participating centre directly received funds for involvement in TREC. GH undertook TREC as part of her work funded by the Ministry of Health, Brazil. TREC was jointly funded by Fundação Osvaldo Cruz, the Cochrane Schizophrenia Group, the British Council, CAPES (Coordenação de Aperfeiçoamento de Pessoal de Nível Superior), and FAPERJ (Fundação de Amparo à Pesquisa do Estado do Rio de Janeiro). All salary funding was intramural. Drugs used in the trial were supplied by the local government through Secretaria Municipal de Saúde do Rio de Janeiro. A computer was given by the Resource Centre for Randomised Controlled Trials (www.rcrt.ox.ac.uk/).

Competing interests: None declared.

Ethical approval: TREC was approved by ethics committees from Escola Nacional de Saúde Pública Fundação Oswaldo Cruz, Instituto Phillipe Pinel, and Hospital Municipal Jurandyr Manfredini, Instituto Municipal de Assistência à Saúde Nise da Silveira and by the members of the Consumer Advocate Group of Rio de Janeiro (SOSINTRA-Society of family and friends of the mentally ill in Rio de Janeiro). TREC was also approved by the National Council of Ethics in Research.

1 McAllister-Williams RH, Ferrier IN. Rapid tranquillisation: time for a reappraisal of options for parenteral therapy. $\mathrm{Br} J$ Psychiatry 2002;180:485-9.

2 Kaplan HI, Sadock BJ, Grebb JA. Kaplan and Sadock's synopsis of psychiatry. 7th ed. Baltimore: Williams and Wilkins, 1994.

3 Expert Consensus Guideline Group. Treatment of schizophrenia 1999. The expert consensus guideline series. J Clin Psychiatry 1999;60(suppl 11):3-80

4 Wing JK, Marriott S, Palmer C, Thomas V. The management of imminent violence: clinical practice guidelines to support mental health services. London: Royal College of Psychiatrists, 1998. (Occasional paper OP41.)

5 Cunnane JG. Drug management of disturbed behaviour by psychiatrists. Psychiatr Bull 1994;18:138-9.

6 Binder RL, McNiel DE. Emergency psychiatry: contemporary practices in managing acutely violent patients in 20 psychiatric emergency rooms. Psychiatr Serv 1999:50:1553-4.

7 Pilowsky LS, Ring H, Shine PJ, Battersby M, Lader M. Rapid tranquillisation. A survey of emergency prescribing in a general psychiatric hospital. BrJ Psychiatry 1992;160:831-5.

8 Moritz F, Bauer F, Boyer A, Lemarchand P, Kerleau JM, Moirot E, et al. [Patients in a state of agitation at the admission service of a Rouen hospital emergency department]. Presse Med 1999;28:1630-4.

9 Huf G, da Silva Freire Coutinho E, Fagundes HM Jr, Oliveira ES, Lopez JR, Gewandszajder M, et al. Current practices in managing acutely disturbed patients at three hospitals in Rio de Janeiro-Brazil: a prevalence study. BMC Psychiatry 2002;2:4. www.biomedcentral.com/1471-244X/ $2 / 4$

10 Coutinho E, Fenton M, Adams C, Campbell C. Zuclopenthixol acetate in psychiatric emergencies: looking for evidence from clinical trials. Schizophr Res 2000;46:111-8.

11 Nestoros JN, Suranyi-Cadotte BE, Spees RC, Schwartz G, Nair NP. Diazepam in high doses is effective in schizophrenia. Prog Neuropsychopharmacol Biol Psychiatry 1982;6:513-6.

12 Battaglia J, Moss S, Rush J, Kang J, Mendoza R, Leedom L, et al. Haloperidol, lorazepam, or both for psychotic agitation? A multicenter, prospective, double-blind, emergency department study. Am J Emerg Med 1997;15:335-40.

13 Joy CB, Adams CE, Lawrie SM. Haloperidol versus placebo for schizophrenia. Cochrane Database Syst Rev 2001;(2):CD003082.

14 Dorevitch A, Katz N, Zemishlany Z, Aizenberg D, Weizman A. Intramuscular flunitrazepam versus intramuscular haloperidol in the emergency 
treatment of aggressive psychotic behavior. Am $J$ Psychiatry $1999 ; 156: 142-4$.

15 World Health Organization. The WHO model list of essential drugs (EDL 1999). www.who.int/medicines/organization/par/edl/infedlmain. shtml (accessed 3 Apr 2002).

16 Jablensky A, Sartorius N, Ernberg G, Anker M, Korten A, Cooper J, et al. Schizophrenia: manifestations, incidence and course in different cultures A World Health Organization ten-country study. Psychol Med Monogr Suppl 1992;20:1-97.

17 Huf G, Coutinho ES, Adams CE. TREC-Rio trial: a randomised controlled trial for rapid tranquillisation for agitated patients in emergency psychiatric rooms [ISRCTN44153243]. BMC Psychiatry 2002;2:11. www.biomedcentral.com/1471-244X/2/11

18 Collaborative Eclampsia Trial Group. Which anticonvulsant for women with eclampsia? Evidence from the collaborative eclampsia trial. Lancet with eclampsia? Evid

19 Altman DG. Confidence intervals for the number needed to treat. $B M$ J 1998;317:1309-12.
20 World Medical Association. World Medical Association Declaration of Helsinki: ethical principles for medical research involving human subjects. 2002. www.wma.net/e/policy/b3.htm (accessed 28 Jul 2003).

21 Council Directive of 4 April 2001. Official Journal of the European Commu nities No L 2001 May 1: 121/34-44. (2001/20/EC.) http://europa.eu.int/ eur-lex/pri/en/oj/dat/2001/_121/1_12120010501en00340044.pdf (accessed 28 Jul 2003).

22 Nuffield Council on Bioethics. wwwnuffieldbioethics.org/home/ (accessed 3 Apr 2002).

23 Fenton M, Coutinho ES, Campbell C. Zuclopenthixol acetate in the treatment of acute schizophrenia and similar serious mental illnesses. Cochrane Database Syst Rev 2001;(3):CD000525.

24 Salzman C, Solomon D, Miyawaki E, Glassman R, Rood L, Flowers E, et al. Parenteral lorazepam versus parenteral haloperidol for the control of psychotic disruptive behavior.J Clin Psychiatry 1991;52:177-80.

(Accepted 10 July 2003) 